\title{
What is the Impact of Feedback as a Central Part of Formative Assessment on Physiotherapy Students Who Have Multiple Educators?
}

\author{
Jane Morris \& Graham Stew \\ University of Brighton, UK \\ Corresponding author: \\ Dr Jane Morris, School of Health Professions, University of Brighton, 49 Darley Road, Eastbourne BN20 \\ 7UR, UK \\ Email: Jm309@brighton.ac.uk, Phone: +44 (0)1273643651
}

\begin{abstract}
The purpose of this study was to gain insight into physiotherapy students experience of feedback as an integral part of formative assessment on placements. A purposive sample of nine physiotherapy students from a pre-registration problem-based learning programme and four physiotherapy practice-based educators was selected. An interpretative phenomenological approach was adopted using in depth semi-structured interviews. Reflective logs and theme boards (memory collages) were used to promote student participants reflection prior to interview. Five main themes emerged from the data: feeling overloaded, challenges of multiple educators, problem-based learning influences, fulfilling experiences, learning through relationships. This paper will focus on two of the main themes:

- challenges of multiple physiotherapy educators,

- learning through relationships.

Lack of communication between educators in a multiple physiotherapy educator model resulted in conflicting feedback that was challenging for students on placement. However, participants valued feedback from other health professionals. Potential exists for more effective use of interprofessional team members to provide feedback as part of ongoing formative assessment. In a changing practice environment where practice educators inevitably face increasing time constraints, use of other team members and peers to provide student feedback should be promoted to facilitate interprofessional ways of working.
\end{abstract}

Keywords: feedback, multiple educator model, communication, interprofessional feedback

\section{Introduction}

In the practice learning environment, health professional students engage in authentic experience that prepares them for future professional life. Within this rich environment they learn how to apply theory to practice effectively, to develop clinical reasoning skills and 
their sense of professional identity (Strohschein et al. 2002, McAllister \& Lincoln 2004, Delany \& Bragge 2009). The rich and diverse range of learning opportunities in practice enables students to develop knowledge, skills and attitudes necessary to facilitate professional growth, and prepares them for their future role as autonomous health professionals (McAllister \& Lincoln 2004, Cross et al. 2006).

Students on placements should experience teaching and learning approaches that include provision of effective feedback in order to benefit from practice-based education opportunities and to ensure that students as future health professionals develop the skills necessary to critically evaluate their practice (Cross et al. 2006). Feedback, an indispensable element of any learning experience, allows learners to compare their own performance with the standard of practice required and may lead to increased motivation (Best \& Rose 2005, Clynes \& Raftery 2008, Van de Ridder et al. 2008). It also helps students to identify their strengths and weaknesses enabling them to reflect and learn from their interaction with patients and other team members, facilitating their ongoing professional development (Cross et al. 2006, Molloy 2009).

"Central to the development of effective learning" (Sadler 2010, p536), feedback is a key component of formative assessment as suggested by Black et al. (2002, p1):

'it provides information to be used as feedback, by teachers, and by their pupils, in assessing themselves and each other... such assessment becomes formative when the evidence is actually used to adapt the teaching work to meet the learning needs'.

In health professional education feedback is considered to be a complex process inextricably linked to continuous formative assessment that takes place during a learning event, motivating and facilitating learning (Rushton 2005, Eraut 2006, Sadler 2010). Feedback, as an essential learning and teaching approach (Poulos \& Mahony 2007, Pelgrin et al. 2012) has a significant impact on student success (Hattie \& Timperley 2007). A seminal paper by Norcini \& Burch $(2007$, p856) recommends that educators think of formative assessment as an 'ongoing process that supports and enhances learning', placing feedback at the centre of formative assessment, as opposed to viewing it as a 'separate educational entity'.

Although feedback is considered to be an essential and flexible tool in practice-based education, it remains one that is often neglected by educators, who fail to recognise its effectiveness in facilitating learning. As Wood $(2000, \mathrm{p} 19)$ suggests, it remains a 'valuable resource, most poorly and infrequently used', with many educators focusing only on providing feedback that corrects mistakes rather than feedback that promotes development and learning (Hattie \& Timperley 2007, Molloy 2009). If educators were to appreciate feedback's facilitative purpose more fully, students might well become more active learners instead of feeling themselves victims of an unrelenting assessment process, where the focus is on meeting criteria and attaining grades (Boud 2000, Torrance 2007).

There is a need for an understanding of the way in which students' interpret and experience feedback. However, most research is related to the role of the educator (Weaver 2006), thereby neglecting the student voice (Carless 2006, Poulos \& Mahony 2007). It is widely acknowledged that extensive research into feedback exists; however, few studies have explored individual learner's experience of formative assessment and related feedback during practice education (Rushton 2005, Molloy \& Clarke 2005, Molloy 2009).

Although other studies have identified beneficial interprofessional learning opportunities for students in practice settings (Hilton \& Morris 2001, Ponzer et al. 2004) currently there is limited data relating to interprofessional feedback opportunities on placement. 
This paper presents some findings from a small-scale interpretative phenomenological study which explored physiotherapy students' experiences of feedback as part of formative assessment during practice-based education. Findings and discussion focus on two main emergent themes. The research focused on two questions:

- How do physiotherapy students experience formative assessment during practice education?

- What are the implications of this for developing the practice of practice educators?

\section{Research Method}

A qualitative interpretative phenomenological approach was used to explore physiotherapy students' experiences of feedback as an integral part of formative assessment during practice education.

A purposive sample of nine participants was selected from physiotherapy students on a pre-registration problem-based learning programme. Four postgraduate practice-based physiotherapy educators were also interviewed to explore the emergent themes.

Student participants kept a reflective log during their placements and completed a theme board (memory collage), which was then used to elicit reflection during the in-depth semi-structured interviews (Butler-Kisber \& Poldma 2009). The face-to-face interview was considered the most appropriate data collection tool for a phenomenological study, allowing the researcher to listen to participants' lived experiences (Kvale \& Brinkmann 2009). Interviews were conducted in a private room on campus when students had completed their placements. Interviews were audio-recorded and transcribed verbatim; field notes were completed after each interview (Lichtman 2006).

An interpretative phenomenological analysis approach (IPA) was used for data analysis which followed a step by step approach proposed by Smith et al. (2009) incorporating both interview data and reflective logs. This gradual approach allowed the researcher (JM) to become immersed in the data (Cresswell 2009, Lichtman 2006) and prevented premature completion of the analysis phase, which may have led to superficial interpretation (Wolcott 2001). A case by case analysis was adopted before common patterns and themes were developed (Smith et al. 2009).

A framework adapted from Yardley (2000) was adopted to ensure rigour and trustworthiness. Substantial extracts from participants were mapped under each theme and the researcher (JM) completed a reflective log during the research process to maintain an open, transparent and reflexive approach (Holstein \& Gubrium 2003). Emergent themes were shared with student participants and practice-based educators to enhance the rigour of the study (Cresswell 2009).

Ethical clearance was sought and gained from the University of Brighton Ethics Committee and all data were treated in accordance with good practice in research and ethics governance (BERA 2008). Participants were given pseudonyms and numbers to protect their identity. In the findings section student quotations are identified by the initial ( $p$ ) and practice-based educators' quotations (pe).

\section{Findings and Discussion}

Two main themes and several sub-themes emerged from the data. In the first theme students' experiences of feedback within a multiple placement model are explored. The second theme 'learning through relationships' focuses on student participants' experience 
of interprofessional feedback. Findings from physiotherapy practice-based educators are also included and discussed.

\section{Students' experiences of feedback within a multiple placement model}

\section{Challenges of multiple educators}

Challenging feedback within a multiple educator model was evidently problematic for some students. The multiple educator model is also known as a multiple mentoring, team or split team model of practice education (Baldry Currens 2000, Lekkas et al. 2007) where two or more educators take responsibility for facilitating and assessing student learning, although there maybe one named lead educator (Stiller et al. 2004). This model is becoming more prevalent in today's practice context where part time practitioners frequently job share. In addition, due to changes in service delivery, educators have a number of different roles often working across different geographical sites some distance apart.

Multiple models of practice-based education have the potential for making students less dependent on an individual educator as such models can promote student autonomy (Lekkas et al. 2007) and offer a variety of assessment and treatment approaches (Stiller et al. 2004). However, findings from this study indicate that conflicting feedback from multiple educators has a negative impact on student learning. For example, one student suggests:

I had multiple educators on two of my placements. One educator would say one thing and the other would say something different and then you do something and your main educator would say 'Oh why are you doing that?' (p 2).

Most student participants found multiple educator models of practice education challenging. Although they recognised the benefits of having more than one educator, their experience of feedback remained less positive. They highlighted the importance of effective communication in order for feedback to be of value.

\section{'Getting inside two people's heads'}

The notion of 'getting inside two people's heads', referred to the difficulties students faced trying to interpret feedback when their placement was facilitated and assessed by more than one educator. A lack of communication between educators made feedback more challenging. Students felt their learning was hindered when educators' feedback conflicted and they were left trying to fathom which educator's approach to follow in order to achieve their learning goals. As a result, a lot of time and energy was spent trying to work out the best approach to ensure they were achieving the standard of practice expected in order to pass the placement.

Andrew reflected on the challenges:

if you have two educators it's almost like two placements, because you have to get inside two people's heads. I found that initially quite a challenge and sometimes things are in contradiction as well, you have to balance that off. $(p, 8)$

However, he also perceived benefits in having more than one educator:

I think that if I'd had one educator I wouldn't have learnt so much... having two, I had twice the amount of resource, to learn and to pull from, I learnt probably twice as much which is fantastic: it's like having two placements. $(p, 8)$ 
Although Andrew initially found feedback 'quite a challenge', he benefited from drawing on the experience of two educators and developed a flexible approach enabling him 'to balance' the disadvantages and advantages, essential skills for future professional practice. In the initial stages of development learners are inevitably looking for correct answers; as their practice develops they begin to accept and integrate different opinions (Perry 1970, Cross et al. 2006). This finding suggests that despite Andrew having to manage some conflicting feedback, he recognised some benefits of having two educators.

Andrew concluded his interview with some thoughts for both educators and students:

from the perspective of the educators, just everything about communication and what you're doing and what they expect of you is doubly important. $(p, 8)$

Anna also recognised the challenges when educators had different expectations:

I just found it a little bit confusing really, one day I'm with a different physio and she had different expectations. (p 4)

However, Anna was able to share an authentic example of a multiple educator model that was successful:

'they worked really well together they were both on the same wavelength .... I'd go and tell her what I was doing l'd feed forward, then at the end of the day I'd feed back to the other educator and they were able to communicate with each other throughout the day, because if they're not communicating as well I think you don't get as much out of the placement' ( $p$ 4)

\section{Acting as a 'go between'}

Anna reflected on acting as a 'go between', adopting the role of a link person facilitating communication between her two educators. This approach seemed to work well, when the placement was well structured and her educators' expectations were clear. By making Anna the link person in the feedback process, her educators made her feel more empowered, as highlighted by Leach et al. (2001). She felt part of the team and was taking responsibility for her own learning, actions that illustrate good practice that supports learning (Wenger 1998, Boud 2000). By promoting self-evaluation and encouraging her to play an active part in the feedback process her educators promoted development of a 'sense of agency' as opposed to Anna feeling herself as a 'passive receiver' (Kluger and Van Dijk 2010, Molloy 2010, p1158). There is potential for developing this model of good practice by adopting a form of feedback log to encourage consistency between educators and to support student self-direction.

\section{The Practice-based Educator Perspective}

Practice-based educators acknowledged the challenges of multiple educator models of practice education. Jo, an experienced practice-based educator, talked about the problems she faced:

It's a real challenge to keep educators coming up with a consistent approach really, when they've got very different styles as well. I find that hard to oversee because I struggle to know what the educators want. (pe,1)

Her experiences resonated with some of the issues identified by student participants. Jo had worked with her team to address some of the difficulties:

I did some teaching with our team... sort of good practice for facilitating formative assessment but they still come up with the same, you know, worries and cons to those, you know, we don't have time to meet up. (pe,1) 
Jo's concerns were also shared by Helen another experienced practice educator:

I do think that can be a really big problem if educators aren't talking to each other. I think that's where maybe documenting feedback can be quite useful because then even if they're not getting a chance to discuss it fully, the student can take something written along to the other educator, to make sure that they're not going to contradict each other. (pe,2)

David identified some problems he faced when trying to delegate responsibility for students to educators who were still 'learning the ropes':

I think the multiple educator model is a reality of the situation we're in.

Educators are being pushed from pillar to post, they don't have one specific role that they do all day and every day, they're all over the place, l've seen the problems if the feedback doesn't happen I've got practice educators who are good but they are learning the ropes. (pe,3)

David placed the challenges in the context of today's increasingly demanding practice environment. As a line manager and lead educator he struggled to support his team of new educators who were being 'pushed from pillar to post'.

Models of practice education involving the whole team are felt to have a number of advantages, these include: decreased student dependency, opportunities for students to experience different approaches, increased resources, more objective assessment, and team integration (Baldry Currens 2000, Bennett 2003, 2008). However, findings from this study suggest that poor communication and inconsistent opinions among educators decrease the quality of feedback that students receive. There are a number of issues that need to be addressed, these include a clear structure, good organisation and effective communication between educators.

Consistent feedback is also essential to prevent students getting confused by differing opinions and so becoming uncertain about their progress. Students who were worried about their final grade found it particularly challenging to 'get inside two peoples' heads' in order to assess their progress. The above findings suggest the focus was on 'assessment of learning' rather than on 'assessment for learning' (Black et al. 2003, Torrance 2007). Students who found themselves in an uncertain position wanted feedback linked to judgement of their performance, as opposed to feedback that facilitated learning and encouraged them to develop more self-evaluative skills.

Bennett's suggestion of a 'learning team model' of practice education involving the whole team including juniors and peers was well received by students (Bennett 2008, p272). In contrast, findings from this study suggest that participants found feedback from more than one educator challenging. However, the multiple educator model in the current study consisted mainly of part time practitioners, or practice-based educators who were working across different sites.

In addition, practice-based educators confirmed that a consistent feedback approach between educators is often difficult to achieve due to factors such as individual personalities, the differing learning styles of educators and difficulties in communication due to working patterns and geographical distances between sites. Nonetheless, multiple educator models of placement are becoming increasingly common with changing service delivery and teams that are continually restructuring. As a result educators and students need to develop strategies to ensure communication remains effective. 


\section{Learning through relationships}

Students' involvement in feedback relationships during formative assessment emerged as an important theme. Within this theme, and in contrast to the previous discussion, students valued learning, working and gaining feedback from other health professionals, which they felt facilitated their learning.

\section{Learning from other disciplines}

There is currently a paucity of evidence supporting interprofessional learning in physiotherapy practice settings, despite the fact that 'the clinical setting is an ideal learning environment for the development of skills conducive to collaborative practice' (Hilton \& Morris 2001, p171).

Students valued the opportunity to learn in an interprofessional team where they were encouraged to think more holistically about their practice. For example, Sally reflected:

'We'd be able to discuss what l'd found about the home situation and it was very holistic... and we worked in a big team as well OTs and nurses and social workers so it was quite nice. You had to think very holistically, and they encouraged that so I found that a very positive experience'. ( $p$ 2)

Feedback from a variety of team members, including social workers, occupational therapists and nurses enabled students to consider alternative ways of working and increased their awareness of professional identity essential to professional learning (Dall'Alba 2009). Interprofessional team members included qualified practitioners, rehabilitation assistants and students from other professions. Students reported benefiting from 'getting their take on things' ( $p 2$ ), it helped them to learn more about treatment approaches used by other professionals. They perceived that they were encouraged to think more creatively about their own assessment and treatments. In addition, the range of different direct and indirect feedback approaches adopted by interprofessional team members promoted a more holistic approach to practice. However, students also felt that there is potential for developing interprofessional feedback through a more focused use of other team members.

For example, potential benefits are explored by Sally:

I think working more very much more in a team and having a lot of time with people rather than your educator because everyone gives you feedback in a different way and I think if you've got time with other professionals like the occupational therapy staff. They can give you their take on things and say well if that were me l'd have done it this way. (p 2)

Feedback from other professionals allowed Sally to experience alternative feedback approaches. This finding is in contrast to an earlier finding, where team members were likened by Anna to 'undercover agents' who provided feedback to her educator rather than directly to her. Anna wanted immediate feedback from another professional, for example an occupational therapist who had observed her communication with a patient during a home visit. She felt that this feedback would enable her to develop her practice as opposed to having to wait for second-hand feedback that was more difficult to place in context. However, Linda, a practice-based educator, suggested that interprofessional team members may be unsure of their role in the feedback process:

Do other professions feel that they might be treading on people's toes by saying something? That's a professional boundary issue. $(p e, 4)$ 
A subtle distinction exists between students who are actively involved as members of a team within a 'community of practice' (Wenger 1998, Green 2005), and for whom feedback forms an integral part of the interprofessional team's role, and students who receive indirect, somewhat covert feedback from team members that is 'recycled' via their educator.

This is an area that needs further exploration. If interprofessional team members are encouraged to provide direct feedback, students should feel more comfortable and accepted as part of the team, supporting a more authentic mode of formative assessment and facilitating students' professional development (Vu \& Dall'Alba 2008). It seems essential in today's health care environment, where practitioners are increasingly managed by professionals from outside their own professional group, that students receive feedback directly from interprofessional team members.

Participants also had the opportunity to learn and work together with occupational therapy students on placements so benefiting from exchange of feedback following joint assessment and treatment of patients.

Simon talks about his experience of working with an occupational therapy student:

I got some feedback off an OT student which was quite interesting ... maybe in terms of a confidence boost to me ... we were working together on one or two patients. It worked quite well and just trying to get the most out of our patients ... I think for me [peer feedback] it's given me sort of more understanding of other people's roles how other people perceive your work as well ... I mean I've got a lot more respect for what they do. I understand more what they're doing and the goals they need to meet and the goals we need to meet and how to work together. $(p$ 6)

Although Simon had contact with occupational therapy students on his course, opportunities for interprofessional learning were limited. Interprofessional peer feedback made him consider his practice in a different way:

I think in terms of feedback they can give maybe just different stuff that you wouldn't have thought of, they may just have a different idea that you haven't considered so it was quite good. (p 6)

As Simon reflected he recognised there may also be efficiency savings for the service and benefits from a patient perspective:

... maybe combining assessments and bringing it together so you get two sessions in one ... if you do a joint assessment I found lots of times I would do my physio assessment and then have to go and speak to the OTs and feedback, whereas if we did it together we'd just discuss it straight away; that was it done. You end up chasing people forever ... it got a bit frustrating because one of my patients was capable to go home but we were waiting for equipment. It [joint working] sort of brings it together and at the end of the day it would have saved time. (p 6)

The occupational therapy student helped Simon to view his practice from a different perspective. Interprofessional peer feedback helped him to identify an area of service development that could inform discharge planning and ultimately impact on the quality of patient care. Simon and his occupational therapy colleague recognised the potential benefits to patients of joint student assessments. These benefits include: preventing duplication of patient assessments, improved quality of discharge planning, and more efficient use of resources. Department of Health Policy document (DH 2010) highlights the need for sustained improvement of patient care and improved interprofessional learning 
and working on placement. Findings from this study indicate that there is potential for interprofessional peer feedback on placements to facilitate changes in practice delivery so leading to innovation and improvement in the patient experience.

At a personal level, through engagement in interprofessional peer feedback, a number of students reported increased confidence, and a deeper understanding of each other's roles (Stew 2005, Hylin et al. 2007, Steven et al. 2007); they valued discussion with their interprofessional peers which helped them to view their own practice from a different perspective. Most research into interprofessional learning on placement has explored learning opportunities that were organised in advance, for example interprofessional training wards (Freeth et al. 2002, Hylin et al. 2007, Mackenzie et al. 2007, Smith \& Seeley 2010, O'Carroll et al. 2012). In contrast interprofessional peer feedback opportunities identified in this study were mostly opportunistic. Potential exists for students to gain from small initiatives that are easy to arrange in both acute and community settings, reducing organisational constraints that have been reported in acute settings (Jackson \& Bluteau 2007).

Mike reflected on the benefits of feedback he received from interprofessional assistant practitioners:

Yeah, um ... a couple of the ... the OTs and physio assistants gave me really good reviews at the end. Some of them had been there for twenty years and had excellent practice knowledge. They gave me some really good feedback on things that that I might bring up with my educator and things I might be able to improve on. They're just 'friendly help' if that makes any sense. ( $p 5$ )

He distinguished between his educator's feedback and that from assistant practitioners, senior support workers in the NHS who work in a range of healthcare settings. Assistants helped him to identify 'things that I might bring up with my educator', adding an alternative dimension to his learning, enabling him to explore aspects of his practice further. Feedback from 'friendly help' was perceived to be more informal, focusing on practice improvement as opposed to grades and helping him to identify questions to take to his educators.

A new suggestion that emerged from the data was the opportunity to adopt an interprofessional mentor, who was not directly involved in students' summative assessment. Students talked about the potential benefits of using interprofessional mentors or another physiotherapy team member to give feedback:

Someone else other than your educator giving feedback as well might be quite helpful or someone separate you could talk to if it wasn't going well... I think if someone's giving grades you don't want to voice things. ( $p$ 2)

Sally suggested that students might speak more freely with someone who was not involved in summatively assessing them. Students are often reluctant to share concerns with educators who are marking them (Molloy 2009). Use of either an interprofessional 'critical friend' or one from a student's own profession may decrease students' stress levels. There are also other potential benefits of using an impartial mentor. For example, if students are struggling to achieve their learning goals, and are receiving inadequate support, this could be dealt with tactfully by an impartial mentor to prevent mounting student concerns.

Current findings evident in occupational therapy literature on 'role emerging placements', in which a student is supervised on a daily basis by educators from a different profession, demonstrate the value of educators from another professional group facilitating placement learning (Clarke 2010).

Data from this study provides evidence of interprofessional learning opportunities related to feedback 'where professions learn with, from and about each other to improve 
collaboration and the quality of care' (Centre for the Advancement of Interprofessional Education, CAIPE 1997, p2) albeit the opportunities occurred on an ad hoc basis (Stew 2005). There is potential for developing more prearranged student-led interprofessional feedback opportunities in practice education.

\section{Limitations of the study}

Although the sample size is deemed acceptable for a phenomenological study this was a small-scale study and participants were from one institution therefore findings are not transferable to a larger population. The researcher was also an academic at the same institution as the student participants. In any future, similar research the design might be enhanced by interviewing students at different stages of their placement.

\section{Conclusion}

Findings from this study suggest there is a need for improved communication within a multiple educator placement model in order to improve the quality of student feedback as part of formative assessment. It is evident that this model is not without its challenges. When students are in receipt of conflicting feedback from a number of educators they tend to focus on the placement mark as opposed to learning from the whole experience and thinking about how they are developing as professionals.

The use of a feedback log by practice-based educators and students could potentially improve communication and consistency of feedback within a multiple educator model and should also promote self-direction by encouraging students to self-evaluate and adopt a more proactive approach when soliciting feedback.

However, students continue to value the wealth of practice knowledge that different educators are able to share and benefit from feedback opportunities with other health professionals, especially from interprofessional peer feedback.

Students also welcome direct and immediate feedback from interprofessional team members as opposed to circuitous feedback received via their educators. As the latter form of feedback is often delayed, students have difficulty putting it in context and relating it to a patient they have been treating. Practice-based educators should encourage other team members to provide more direct immediate feedback to students and students should actively engage in interprofessional peer feedback on placement as it provides a rich source of learning.

However, educators in higher education need to acknowledge the increasing demands placed on educators in practice, and to ensure that they are supported in facilitating and developing contemporary models of practice-based education. In today's health and social care context, where patient care is delivered by a range of health and social care practitioners working in interprofessional teams, it is essential that students have the opportunity to gain feedback from other team members, both of their own and other professions and to use it effectively to develop their practice.

\section{References}

Baldry Currens, J. (2000) Evaluation of clinical placement models for undergraduate physiotherapy students. University of East London.

Bennett, R. (2003) Clinical education: perceived abilities /qualities of clinical educators and team supervision of students. Physiotherapy 89 (7), 432-442. 
Bennett, R. (2008) Maintaining the quality of clinical education in physiotherapy. Thesis submitted to the University of Birmingham. Available at http://etheses.bham.ac.uk/204/1/ Bennett08PhD_A1b.pdf (accessed 10 November 2010).

Best, D. and Rose, M. (eds.) (2005) Transforming practice through clinical education, professional supervision and mentoring. London: Elsevier Churchill Livingstone.

Black, P., Harrison, C., Lee, C. et al. (2002) Working inside the black box: assessment for learning in the classroom. London: nfer Nelson.

Black, P., Harrison, C., Lee, C. et al. (2003) Assessment for learning: putting it into practice. Buckingham: Open University Press.

British Educational Research Association (BERA) (2008) Guidelines [online] Available at http://www.bera.ac.uk/ethics-and-educational-research-2 (accessed 3 April 2011).

Boud, D. (2000) Sustainable assessment: rethinking assessment for the learning society. Studies in Continuing Education 22 (2), 1-17.

Butler-Kisber, L. and Poldma, T. (2009) The power of visual approaches in qualitative inquiry: the use of collage making and concept mapping in experiential research, International Conference DRS Special Interest Group on experiential knowledge. Available at http://web. me.com/niedderer/EKSIG/conference_proceedings_files/EKSIG09_proceedings_finals (accessed 10 March 2010).

Carless, D. (2006) Differing perceptions in the feedback process. Studies in Higher Education 31 (2), 219-233.

Centre for the Advancement of Interprofessional Education (CAIPE) (1997). Interprofessional education: a definition. London: CAIPE Bulletin. 13, 19.

Chartered Society of Physiotherapy (CSP) (2002) Guidelines for implementing team and split placement models in physiotherapy practice placements. Information paper No. CE6. London: CSP.

Clarke, C. (2010) Preparing students for practice in new and innovative settings.

Occupational Therapy News 18 (7), 31.

Clynes, M.P. and Raftery, S.E.C. (2008) Feedback: an essential element of student learning in clinical practice. Nurse Education in Practice 8, 405-411.

Cresswell, J.W. (2009) Research design. Qualitative, quantitative and mixed methods approaches. 3rd edn, London: Sage.

Cross, V., Moore, A., Morris, J., Caladine, L., Hilton, R. and Bristow, H. (2006)

The practice-based educator a reflective tool for CPD and accreditation. Chichester: Wiley.

Dall'Alba, G. (2009) Learning professional ways of being: ambiguities of becoming.

Educational Philosophy and Theory 41 (1), 34-45.

Delany, C. and Bragge, P. (2009) A study of physiotherapy students' and clinical educators' perceptions of learning and teaching. Medical Teacher 31, e402-e411.

Department of Health White Paper (2010) Equity and excellence. Liberating the NHS.

Available at http://www.dh.gov.uk/prod_consum_dh/groups/dh_digitalassets/@dh/@en/@ps/ documents/digitalasset/dh_117794.pdf.

Eraut, M. (2006) Feedback. Learning in Health and Social Care 5 (3), 111-118.

Freeth, D., Reeves, S., Goreham, C. et al. (2002) 'It teaches you what to expect in future': interprofessional learning on a training ward for medical, nursing, occupational therapy and physiotherapy students. Medical Education 36, 337-344. 
Green, P (2005) Spaces of influence: a framework for analysis of an individual's contribution within communities of practice. Higher Education Research \& Development 24 (4), 293-307.

Hattie, J. and Timperley, H. (2007) The power of feedback. Review of Educational Research 77 (1), 81-112.

Hilton, R. and Morris, J. (2001) Student placement, Is there evidence supporting team skill development in clinical practice settings? Journal of Interprofessional Care 17 (1), 21-34.

Holstein, J. A. and Gubrium, J.F. (2003) Inside interviewing, new lenses, new concerns. London: Sage.

Hylin, U., Nyholm, H., Mattiasson, A-C et al. (2007) Interprofessional training in clinical practice on a training ward for healthcare students: a two-year follow-up, Journal of Interprofessional Care 21 (3), 277-288.

Jackson, A. and Bluteau, P. (2007) At first it's like shifting sands: setting up interprofessional learning within a secondary care setting. Journal of Interprofessional Care 21 (3), 351-353.

Kluger, A.N. and Van Dijk, D. (2010) Feedback, the various tasks of the doctor, and the feed forward alternative. Medical Education 44, 1166-1174.

Kvale, S. and Brinkmann, S. (2009) Interviews: learning the craft of qualitative research interviewing. London: Sage.

Leach, L., Neutze, G. and Zepke, N. (2001) Assessment and empowerment: some critical questions. Assessment and Evaluation in Higher Education. 26 (4), 293-305.

Lekkas, P., Larsen, T., Kumar, S., Karen, K., Nyland, L., Chipchase, L., Jull, G., Buttrum, P., Carr, L., Finch, J. (2007) No model of clinical education for physiotherapy students is superior to another: a systematic review. Australian Journal of Physiotherapy 52, 19-28.

Lichtman, M. (2006) Qualitative research in education. A user's guide. London: Sage.

Mackenzie, A., Craik, C., Tempest, S. et al. (2007) Interprofessional learning in practice: the student experience. British Journal of Occupational Therapy 70 (8), 358-361.

McAllister, L. and Lincoln, M. (2004) Clinical education in speech-language pathology. London: Whurr.

Molloy, E. and Clarke, D. (2005) The positioning of physiotherapy students and clinical supervisors in feedback sessions. Focus on Health Professional Education: A MultiDisciplinary Journal 7 (1), 79-90.

Molloy, E. (2009) Time to pause: giving and receiving feedback in clinical education. In Clinical education in the health professions (eds. C. Delaney and E. Molloy). London: Churchill Livingstone Elsevier.

Molloy, E.K. (2010) The feedforward mechanism: a way forward in clinical learning? Medical Education 44, 1157-1159.

Norcini, J. and Burch, V. (2007) Workplace-based assessment as an educational tool. AMEE Guide No 31. Medical Teacher 29 (9), 855-871.

O'Carroll, V., Braid, M., Ker, J. and Jackson, C. (2012) How can student experience enhance the development of a model of interprofessional clinical skills education in the practice placement setting? Journal of Interprofessional Care 26, 508-510.

Pelgrin, A.M., Kramer, W.M., Mokkink Henk, G.A. and van der Vleuten, Cees P.M. (2012) The process of feedback in work-based assessment: organisation, delivery, continuity. Medical Education 46, 604-612. 
Perry, W. (1970) Forms of intellectual and ethical development in the college years. New York: Holt, Rinehart \& Winston.

Ponzer, S., Hylin, U., Kusoffsky, A., et al. (2004) Interprofessional training in the context of clinical practice goals and students' perceptions on clinical education wards, Medical Education 38 (7), 727-736.

Poulos, A. and Mahony, M. J. (2007) Effectiveness of feedback: The students' perspective. Assessment \& Evaluation in Higher Education 33, 143-154.

Rushton, A. (2005) Formative assessment: a key to deep learning? Medical Teacher 27 (6), 509-513.

Sadler, R. (2010) Beyond feedback: developing the student capability in complex appraisal. Assessment \& Evaluation in Higher Education 35 (5), 535-550.

Smith, J.A., Flowers, P. and Larkin, M. (2009) Interpretative phenomenological analysis. Theory, method and research. London: Sage.

Smith, J.A. and Osborn, M (2003) Interpretative phenomenological analysis. In Qualitative psychology: a practical guide to methods (ed. J.A. Smith), pp51-80 London: Sage.

Smith, P.M. and Seeley, J (2010) A review of the evidence for the maximization of clinical placement opportunities through interprofessional collaboration. Journal of Interprofessional Care 24 (6), 690-698.

Stew, G. (2005) Learning together in practice: a survey of interprofessional education in clinical settings in South-East England. Journal of Interprofessional Care 19, 223-235.

Steven, A., Dickinson, C. and Pearson, P. (2007) Practice-based interprofessional education: looking into the black box. Journal of Interprofessional Care 21 (3), 251-264.

Stiller, K., Lynch, E., Phillips, A. et al. (2004) Clinical education of physiotherapy students in Australia. Perceptions of current models. Australian Journal of Physiotherapy 50, 243-247.

Strohschein, J., Hagler, P. and May, L. (2002) Assessing the need for change in clinical education practices. Physical Therapy 82 (2), 160-172.

Torrance, H. (2007) Assessment as Learning? How the use of explicit learning objectives, assessment criteria and feedback in post-secondary education and training can come to dominate learning. Assessment in Education 14 (3), 281-294.

Van de Ridder, J.M., Stokking, K.M., McGaghie, W.C. et al. (2008) What is feedback in clinical education? Medical Education 42, 189-197.

$\mathrm{Vu}, \mathrm{T}$.T. and Dall'Alba, G. (2008) Exploring an authentic approach to assessment for enhancing student learning. In AARE 2008: Changing climates: education for sustainable futures (ed. P.L. Jeffery). AARE 2008 International Education Research Conference, Queensland University of Technology, Kelvin Grove (1-11), 30 November to 4 December.

Weaver, M.R. (2006) Do students value feedback? Student perceptions' of tutors' written responses. Assessment \& Evaluation in Higher Education 31 (3), 379-394.

Wenger, E. (1998) Communities of practice. Learning meaning and identity. Cambridge: Cambridge University Press.

Wolcott, H.F. (2001) writing up qualitative research. London: Sage.

Wood, B.P. (2000) Feedback: a key feature of medical training. Radiology 215, 17-19.

Yardley, L. (2000) Dilemmas in qualitative health research. Psychology \& Health 15, 215-228. 